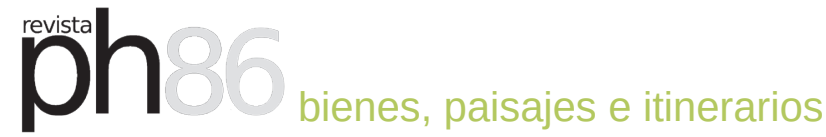

\section{Las fortalezas de Belalcázar}

Alberto León Muñoz | Dpto. de Historia del Arte, Arqueología y Música, Universidad de Córdoba

URL de la contribución <www.iaph.es/revistaph/index.php/revistaph/article/view/3508>

\section{RESUMEN}

En este texto se realiza un sucinto repaso por las principales fases constructivas detectadas en el recinto amurallado y en el castillo de Belalcázar, que presentan una secuencia de ocupación desde, al menos, el siglo IX hasta finales del siglo XV. Las estructuras conservadas constituyen una buena síntesis de la historia medieval de la comarca del valle de los Pedroches. Desde la etapa de consolidación de la dinastía omeya en un territorio periférico, pasando por su valor estratégico como fortaleza de carácter fronterizo, y la definitiva conquista castellana, hasta la conformación del señorío nobiliario a mediados del siglo $\mathrm{XV}$, todos estos episodios históricos dejaron una indeleble huella en el registro material. Sin embargo, la monumentalidad del castillo bajomedieval ha atraído todas las miradas y no en vano constituye uno de los ejemplos más conspicuos de la arquitectura defensiva medieval hispana.

\section{Palabras clave}

Andalucía | Belalcázar (Córdoba) | Castillo de Gahete | Comarca de los Pedroches | Córdoba (Provincia) | Fortificaciones | 


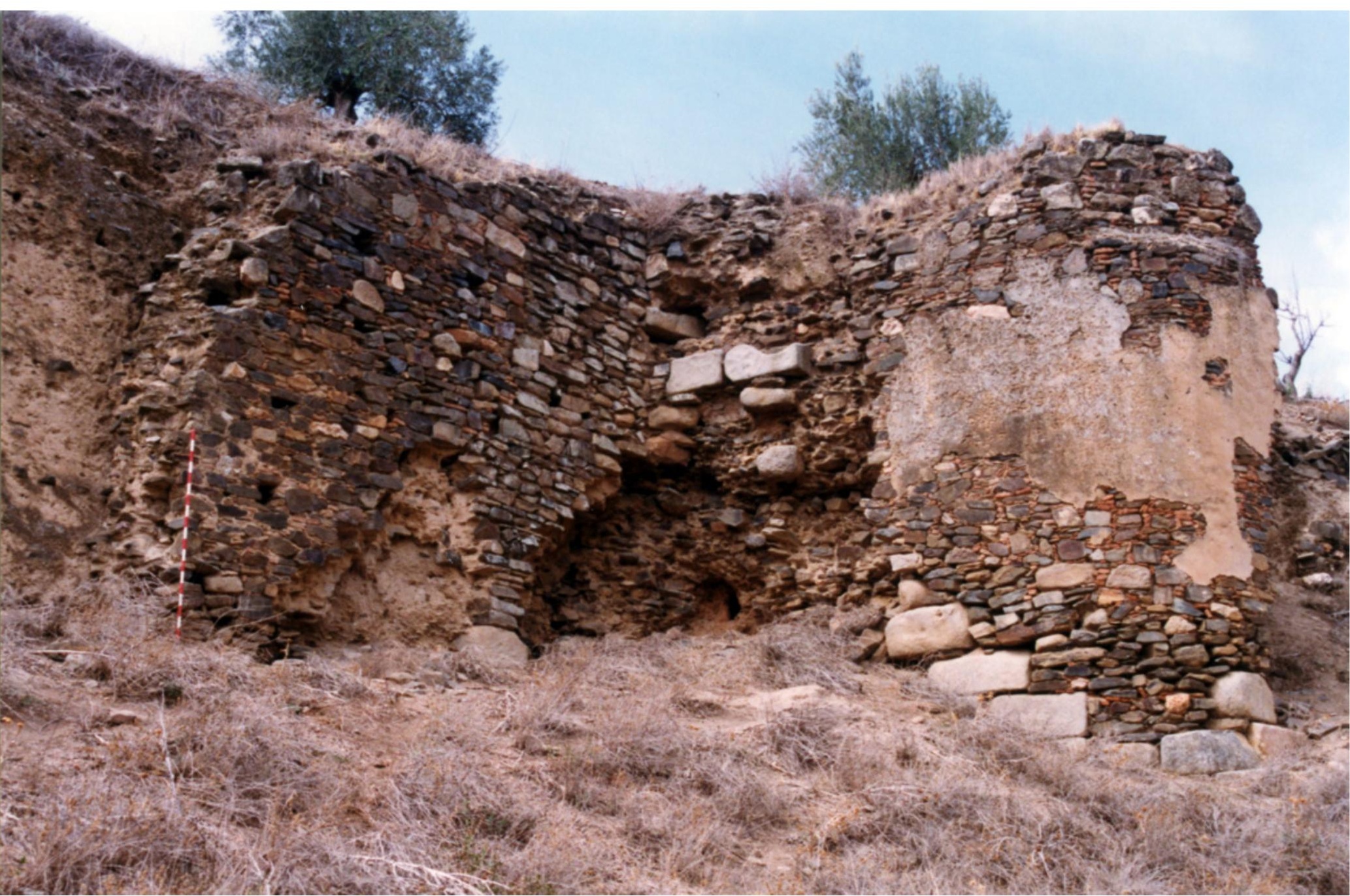

Detalle de uno de los lienzos del recinto amurallado exterior de Belalcázar. Se aprecian la reutilización de materiales constructivos romanos en una torre de probable cronología emiral y las reformas bajomedievales | foto Alberto León (de todas las imágenes del artículo) 


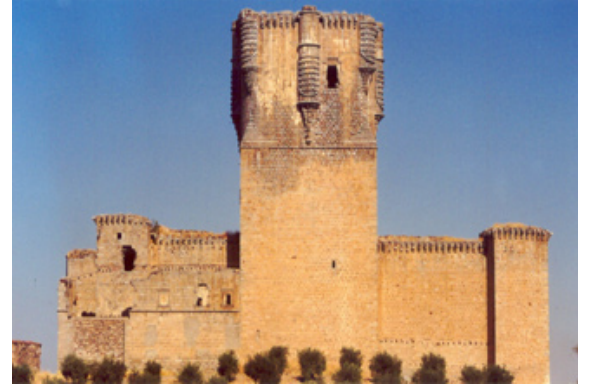

Detalle del cuerpo superior ochavado de la torre de homenaje con las escaraguaitas decoradas con el emblema de los Sotomayor
En el extremo occidental del valle de los Pedroches, en uno de los puntos a partir de los cuales la penillanura granítica cambia a una orografía algo más accidentada con un substrato geológico caracterizado por el predominio de la pizarra, se yergue, visible desde varios kilómetros de distancia, la monumental torre del homenaje del castillo de Belalcázar. El cuerpo superior ochavado de dicha mole arquitectónica, rematada en el último cuarto del siglo $\mathrm{XV}$, es el culmen de una sucesión de fortificaciones que desde el siglo IX se erigieron en este enclave. Tal es así que la historia medieval de la comarca de los Pedroches puede sintetizarse, en gran medida, en la evolución de las fortalezas de las que aún se conservan valiosísimos vestigios constructivos.

El lugar elegido para su emplazamiento fue una suave loma amesetada, que no destaca especialmente en el entorno por su altitud, pero de un especial valor estratégico, al estar rodeada en tres de sus lados por el curso del arroyo Caganchas, un excelente recurso defensivo natural. El conjunto fortificado está formado, básicamente, por dos elementos principales: el recinto exterior, en un deteriorado estado de conservación, que apenas ha sido objeto de atención, ensombrecido por la monumentalidad del segundo gran bloque, el castillo señorial de los Sotomayor. Sin embargo, ambos edificios constituyen testimonios excepcionales en el panorama andaluz en lo relativo a la arquitectura defensiva medieval.

En época emiral se fundó en este lugar una medina conocida como Gafiq, que contaba con su propia alcazaba, construida con piezas de granito reutilizadas de edificios romanos, acaso procedentes del cercano yacimiento identificado como el posible municipio de Baedro, a la manera de la alcazaba de Mérida, erigida en estas mismas fechas. En un entorno de población beréber, en la ruta de Córdoba a Mérida, la fortaleza omeya de Gafiq garantizaba el control de un extenso territorio de vital importancia para los gobernantes cordobeses.

Tras la descomposición del califato omeya cordobés, en el siglo XI esta fortaleza quedó encuadrada en un territorio fronterizo entre diferentes reinos de Taifas (Badajoz, Sevilla y Toledo), por lo que fue objeto de nuevas obras de refortificación con lienzos de mampuestos de pizarra de la zona.

Con la toma de Toledo por Alfonso VI, en 1085, se inició una etapa de inestabilidad en el territorio al sur del Tajo, como consecuencia de las esporádicas razias y campañas de saqueo de las tropas castellanas por Sierra Morena. Gafiq quedó convertida en una fortaleza que vio reducida su población, pero no su valor defensivo, pues en las fuentes islámicas destacó como una plaza ocupada por aguerridos luchadores musulmanes dedicados a practicar la yihad frente a los enemigos cristianos. Para ello reforzaron sus defensas con lienzos levantados en tapiales sobre zócalos de mampuestos, provistos de torres albarranas para la defensa de los puntos más débiles del recinto. 


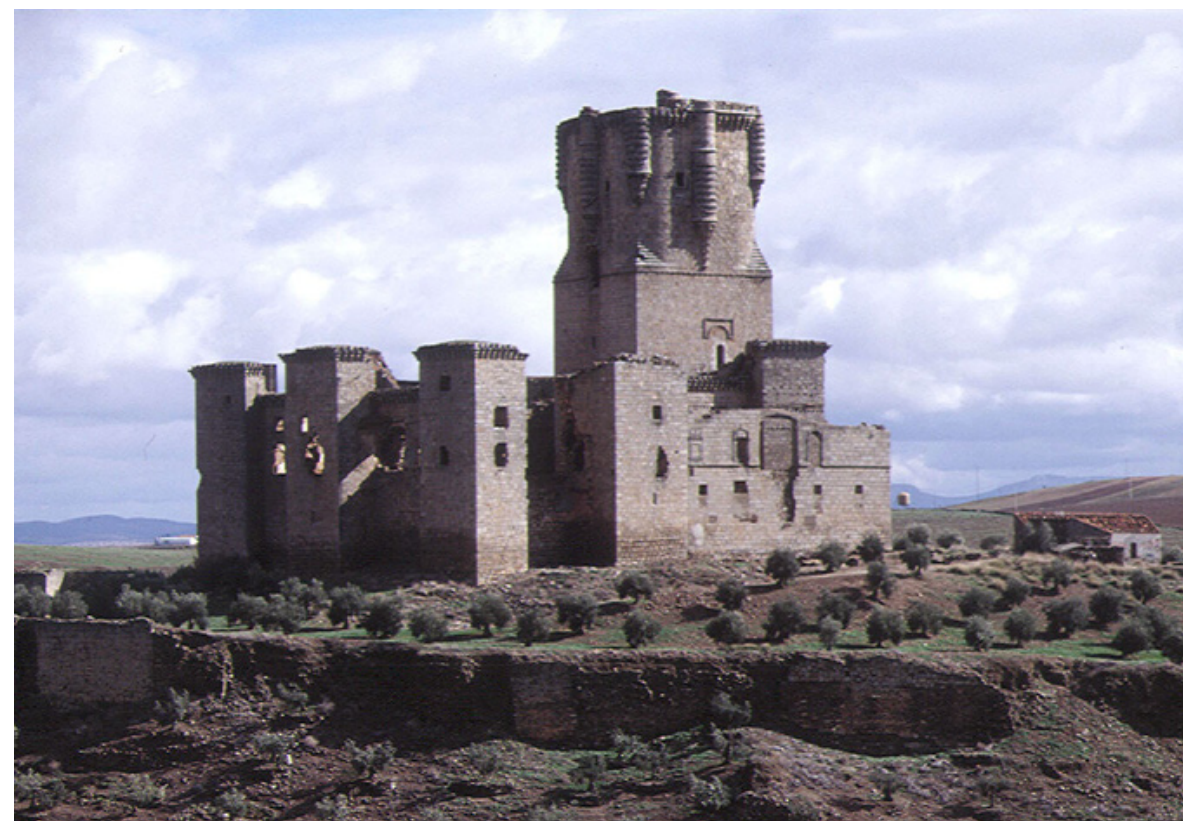

Vista general del castillo y el recinto amurallado de Belalcázar desde el suroeste

En estas condiciones se mantuvo bajo dominio almohade hasta la conquista castellana en torno a 1240.

Ya en manos cristianas, el enclave cambió su nombre por el de Gahete y fue cedido para su ocupación y repoblación al propio concejo de Córdoba. Las obras acometidas durante los siglos XIII y XIV se limitaron a la reparación de sus muros con forros de mampostería, pues pronto decayó su valor estratégico al trasladarse la frontera al sur del Guadalquivir. Sin embargo, su interés como zona de riqueza ganadera no pasó nunca desapercibida para los miembros de la nobleza urbana cordobesa, quienes se disputaron el dominio sobre sus pastos y sus rentas. Los magistrales estudios del profesor Emilio Cabrera (1977) han permitido reconstruir los diferentes intentos de usurpación de estas tierras por parte de los veinticuatros de Córdoba, una de las causas que, en el contexto de las luchas nobiliarias acaecidas a mediados del siglo XV, provocaron la cesión de Gahete, por parte de Juan II en 1444, como villa de señorío, al maestre de la orden de Alcántara, don Gutierre de Sotomayor.

Si bien tradicionalmente se ha venido atribuyendo la construcción del nuevo castillo señorial a don Gutierre, por ser el fundador del señorío, el personaje más relevante del linaje y quien acumuló la fortuna necesaria para acometer tan monumental obra, no hay ningún documento escrito que confirme esta asignación. Por otro lado, las características arquitectónicas del flamante edificio, erigido en el punto más elevado de la meseta del cerro, muestran evidentes diferencias con respecto a las otras dos fortificaciones extremeñas claramente atribuidas a su promoción: los castillos de Puebla 
de Alcocer y Herrera del Duque. En el caso que nos ocupa, el castillo consiste en un recinto de planta cuadrangular, ligeramente irregular, construido en sillería de granito, con ocho torres de flanqueo, macizas en las esquitas y huecas y habitables en el centro de los lienzos, dotado de una gran torre del homenaje cuadrada, de unos $17 \mathrm{~m}$ de lado, en su flanco oriental. Este primer edificio era tremendamente austero, sin apenas concesiones decorativas, con escasísimos huecos al exterior, tan sólo la puerta de ingreso abierta en su flanco norte, y con estrechas aspilleras y reducidas ventanas en las habitaciones superiores de las torres de flanqueo. El castillo de Belalcázar, nueva denominación adquirida a partir de este momento como consecuencia de su monumentalidad, se vincula directamente con otras construcciones extremeñas y castellanas integradas en el condado de Plasencia; en particular, con la fase inicial del castillo de Oropesa, en Toledo.

Por esta razón, parece más plausible retrasar su construcción tras la muerte del maestre de Alcántara, don Gutierre, acaecida en 1453, y adscribirla a don Alfonso de Sotomayor y su esposa, doña Elvira de Zúñiga, hija del conde de Plasencia. Este primer edificio responde a la necesidad de mantener las tierras del señorío frente a los fallidos intentos de recuperación violenta por parte de los miembros de la nobleza cordobesa.

Pero los accidentados avatares del linaje tras la repentina muerte de su titular, en 1464, provocaron que la tutoría del señorío quedara en manos de una mujer sobresaliente, doña Elvira, quien logró la consolidación del señorío gracias a una actitud prudente y sumamente inteligente.

Esta actuación se materializó en una intensa remodelación de la primitiva fortaleza que quedó transformada en un impresionante edificio de carácter palatino, dotado de un vistoso patio porticado con alfarjes ricamente ornamentados, amplios ventanales al exterior y, sobre todo, con el recrecido de los dos pisos superiores de la torre del homenaje, hasta alcanzar los $47 \mathrm{~m}$ de altura, provista de ocho escudos con el emblema de los Sotomayor labrados en las monumentales escaraguaitas.

El sutil manejo del lenguaje simbólico de la arquitectura, que encuentra en Belalcázar uno de sus más llamativos ejemplos, logró los fines para los que se planificó la fortaleza, la legitimación del linaje y la continuidad del señorío. Aún hoy, más de cuatrocientos años después, sigue causando el mismo impacto en el visitante, pese a su estado de conservación. Este sucinto recorrido evidencia, no obstante, el interés del conjunto fortificado y la necesidad de abordar un programa de intervenciones que garantice su conservación para el futuro. 


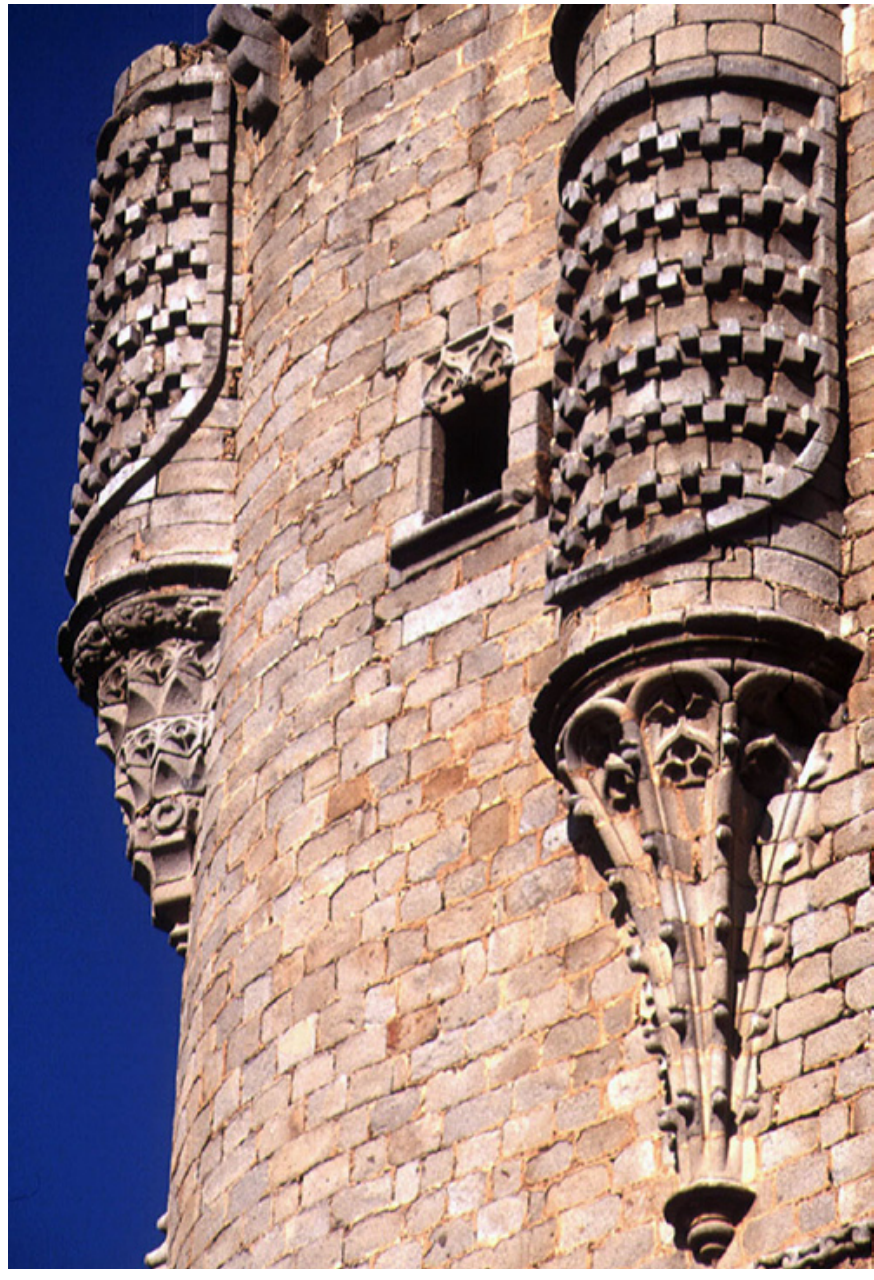

Detalle de la decoración arquitectónica de las escaraguaitas de la torre del homenaje

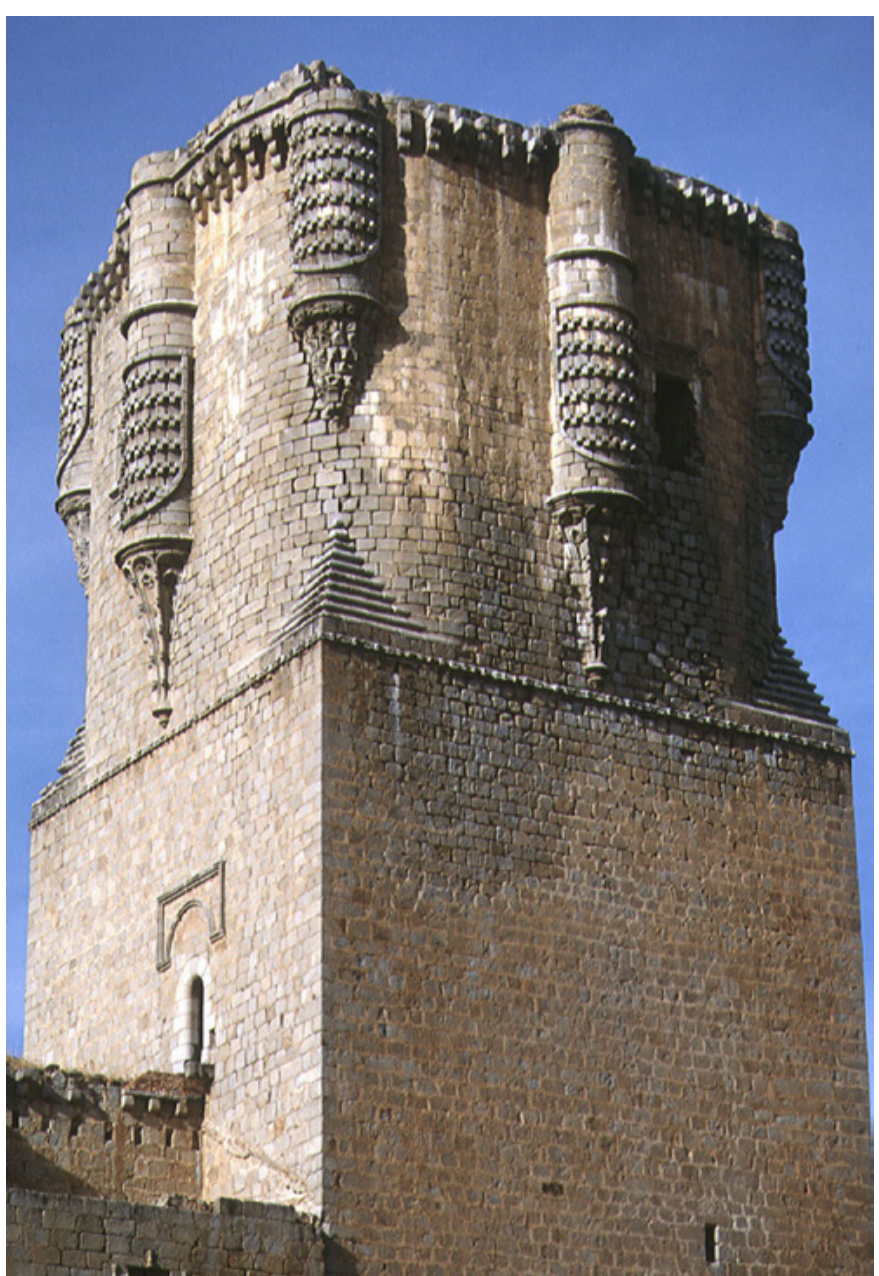

Detalle de la torre del homenaje desde su costado oriental

\section{BIBLIOGRAFÍA}

- CABRERA MUÑOZ, E. (1977) El Condado de Belalcázar (1444-1518). Aportación al estudio del régimen señorial en la Baja Edad Media. Córdoba: Monte de Piedad y Caja de Ahorros de Córdoba, 1977

- LEÓN MuÑoz, A. (2003) Las fortalezas de Belalcázar. Análisis arqueológico de su arquitectura (siglos IX-XIX). Córdoba: Diputación de Córdoba. Delegación de Cultura, 2003 